\title{
Theoretical Study of Water Saturation with Percolation Mechanics Method
}

\author{
Z.B. Liu ${ }^{1}$, H.H. Liu ${ }^{* 2}$ and X.F. Ding ${ }^{3}$ \\ ${ }^{I}$ School of Graduate, Southwest Petroleum University, Chengdu, China; ${ }^{2}$ School of Petroleum Engineering, Southwest \\ Petroleum University, Chengdu, China; ${ }^{3}$ School of Science, Southwest Petroleum University, Chengdu, China
}

\begin{abstract}
Theoretical study of water saturation in oil-water fluid flow area is meaningful to the high, stabilized production and the improvement of ultimate recovery. At present, there is no theoretical description of water saturation in the oil and water seepage process. Combining relational expression between relative permeability and water saturation with the fractional flow equation produces an expression of water cut changed by water saturation; Introducing Taylor expansion and Vieta's theorem to the differentiation of water cut gives a theoretical expression of water saturation in oilwater fluid flow area; Possibility of continuity of the water saturation is also discussed. Applying this formula to certain sandstone reservoir in China achieves good results: In oil-water seepage process, water saturation is continuous in certain interval and the values of it are double in another interval; the oil recovery can be re-calculated and improved with this new equation. This new water saturation equation lays a base for the study of residual oil mobility and enhanced oil recovery.
\end{abstract}

Keywords: Relative permeability, water saturation, percolation mechanics, Buckley-Leverett equation, Vieta's Theorem

\section{INTRODUCTION}

Buckley-Leverett (1942) proposed the Buckley-Leverett equation [1], but we cannot deduce the theoretical expression of water saturation from it. Since then, many scholars began to study the water saturation and already made some progress. The previous study was based on the experimental method, Archie (1942) established a formula of water saturation adaptive to these pure sandstone reservoirs [2]; Poupon's work (1971) [3] was based on Simandoux's which was done in 1983 [4], where an equation of water saturation was given. Fertl (1982) [5] and Dewan (1998) [6] further developed the above-mentioned equation. Yao (1993) et al used the analytical forecasting method to study the water saturation of reservoir [7]; Zhang et al (2008) theoretically deduced the relation between electric resistivity and water saturation [8]; Wang et al (2010) [9] and Li (2010) [10] also studied the water saturation of oil reservoirs with the experimental method, respectively. However, there is seldom theoretical research on water saturation based on the percolation mechanics method. In this paper, we aim to propose a new theoretical expression of water saturation based on percolation mechanics.

\section{ASSUMPTIONS}

(1) oil-water fluid flow;

(2) homogeneous porous media;

(3) incompressible rock and liquid;

*Address correspondence to this author at the School of Petroleum Engineering, Southwest Petroleum University, Chengdu, China; Tel: +0086-028-83032760; E-mail:Tsinghua616@163.com
(4) obey the Darcy's law;

(5) satisfy the 1D Buckley-Leverett equation;

(6) follow the law of conservation of mass.

\section{QUANTITATIVE DESCRIPTION OF WATER SATURATION}

A. Quantitative Description of Water Saturation

He, G.S's work (1994) [11] refers

$\frac{k_{o}}{k_{w}}=a e^{-b S_{w}}$

By introducing Eq. (1) to the fractional flow equation gives

$$
f_{w}=\frac{1}{1+M a e^{-b s_{w}}}
$$

Where coefficients $a, b$ are determined by properties of rock and fluid and can be solved by graphical method.

The Buckley-Leverett equation is a transport equation used to model two-phase flow in porous media. The Buckley-Leverett equation or the Buckley-Leverett displacement can be interpreted as a way of incorporating the microscopic effects to due capillary pressure in two-phase flow into Darcy's law. In a 1D sample (control volume), let $S_{w}$ be the water saturation, then the Buckley-Leverett equation is

$\frac{d x}{d t}=\frac{q(t)}{\phi A} \frac{d f_{w}}{d S_{w}}$ 
Introducing integration to Eq. (3) gives

$\frac{\phi A}{W(t)}\left(x-x_{0}\right)=f_{w}^{\prime}\left(S_{w}\right)$

When $x=x_{0}$ (initial place of oil-water seepage flow area), $S_{w}=1-S_{o r}$.

Introducing the differentiation of Eq. (2) to Eq. (4) gives $\frac{\phi A}{W(t)}\left(x-x_{0}\right)\left(1+M a e^{-b S_{w}}\right)^{2}=M a b e^{-b S_{w}}$

By setting $y=e^{-b S_{w}}$ in Eq. (5) gives

$\frac{\phi A}{W(t)}\left(x-x_{0}\right) M^{2} a^{2} y^{2}+\left(2 M a \frac{\phi A}{W(t)}\left(x-x_{0}\right)-M a b\right) y+\frac{\phi A}{W(t)}\left(x-x_{0}\right)=0$

Let $\frac{\phi A}{W(t)}\left(x-x_{0}\right) M^{2} a^{2}=A_{1}, 2 M a \frac{\phi A}{W(t)}\left(x-x_{0}\right)-M a b=A_{2}, \frac{\phi A}{W(t)}\left(x-x_{0}\right)=A_{3}$ produces a quadratic equation $A_{1} y^{2}+A_{2} y+A_{3}=0$.

Solving the quadratic equation and taking the natural logarithm gives

$S_{w}=\frac{1}{b} \ln \left(\frac{2 \phi A\left(x-x_{0}\right) M a}{\left.-\left[2 \phi A\left(x-x_{0}\right)-b W(t)\right]+W(t) \sqrt{b\left[b-\frac{4 \phi A}{W(t)}\left(x-x_{0}\right)\right.}\right)}\right), 0<x-x_{0}<\frac{b W(t)}{4 \phi A}$
$S_{w}=\frac{1}{b} \ln \left(\frac{2 \phi A\left(x-x_{0}\right) M a}{-\left[2 \phi A\left(x-x_{0}\right)-b W(t)\right]-W(t) \sqrt{b\left[b-\frac{4 \phi A}{W(t)}\left(x-x_{0}\right)\right]}}\right), 0<x-x_{0}<\frac{b W(t)}{4 \phi A}$

When $x_{x=x_{0}}+\frac{b W(t)}{4 \phi A}$, Eq. (7) and Eq. (8) gives $S_{w}=\frac{\ln (M a)}{b}$

Here, $x_{f}=x_{0}+\frac{b W(t)}{4 \phi A}$ is the location of frontal zone in time $t$. This formula shows that the location of frontal zone goes forward with the increase of oil production, and the water saturation $S_{w f}=\frac{\ln (M a)}{b}$ should be frontal water saturation.

Introducing the inequality $1 \geq S_{w} \geq 0$ to Eq. (7) gives $\frac{b W(t)}{2 \phi A(M a+1)} \leq x-x_{0} \leq \frac{b W(t)}{4 \phi A}$.

This means the product of total water injected and permeability ratio-saturation slope is less or equal to four times the volume of reservoir that has been flooded. This also refers to the displacement efficiency.

Hence,

$S_{n}=\frac{1}{b} \ln \left(2 \phi A\left(x-x_{0}\right) M a /-\left[2 \phi A\left(x-x_{0}\right)-b W(t)\right]+W(t) \sqrt{b\left[b-\frac{4 \phi A}{W(t)}\left(x-x_{0}\right)\right]}\right), \frac{b W(t)}{2 \phi A(M a+1)} \leq x-x_{0} \leq \frac{b W(t)}{4 \phi A}$

Introducing the inequality $1 \geq S \geq 0$ to Eq. (8) gives $\frac{b W(t)}{\phi A} \frac{M a e^{b}}{\left(M a+e^{b}\right)^{2}} \leq x-x_{0} \leq \frac{b W(t)}{4 \phi A}$

Hence,

$S_{w}=\frac{1}{b} \ln \left(2 \phi A\left(x-x_{0}\right) M a /-\left[2 \phi A\left(x-x_{0}\right)-b W(t)\right]-W(t) \sqrt{b\left[b-\frac{4 \phi A}{W(t)}\left(x-x_{0}\right)\right]}\right) \cdot \frac{b W(t)}{\phi A} \frac{M a e^{e}}{\left(M a+e^{e}\right)^{2}} \leq x-x_{0} \leq \frac{b W(t)}{4 \phi A}$

\section{B. Possibility of Continuity}

The above-mentioned deduction of water saturation shows: the function of water saturation is continuous in interval $\left[\frac{b W(t)}{\phi A} \frac{M a e^{b}}{\left(M a+e^{b}\right)^{2}}, \frac{b W(t)}{2 \phi A(M a+1)}\right)$; the value of water saturation in interval $\left[\frac{b W(t)}{2 \phi A(M a+1)}, \frac{b W(t)}{4 \phi A}\right)$ is multiple. Here, Possibility of continuity of water saturation function below at $x-x_{0}$ should be investigated. When $x$ approaches to $x_{0}$, $f_{w}$ approaches to zero, it is, in Eq.(2), we see that $b$ approaches to infinity. So the water saturation value at $X=x_{0}$ is the value at $x=\frac{b W(t)}{\phi A} \frac{M a e^{b}}{\left(M a+e^{b}\right)^{2}}$.

Note: if there is irreducible water saturation or residual oil saturation, the inequality should be $1-S_{n} \geq S_{w} \geq S_{\text {. }}$. And the function of water saturation can be discussed like the abovementioned process.

\section{Improved Oil Recovery}

Oil recovery is denoted by $E_{R}, E_{R}=\frac{1-S_{w}-S_{w}}{1-S_{w}}$, so in oil-water seepage flow area, $E_{R}$ can be calculated with the new expression of water saturation. And through changing certain parameter like $\phi, A, W(t)$,etc, the value of $E_{R}$ can also be changed.

\section{APPLICATION AND DISCUSSION}

Given the water and oil permeability and practical development data of certain sandstone oil reservoir, see Table $\mathbf{1}$ and Table $\mathbf{2}$.

Table 1. Water and Oil Permeability Data of a Sandstone Oil Reservoir

\begin{tabular}{|c|c|c|c|c|c|c|c|c|c|c|c|c|}
\hline$S_{w}, \boldsymbol{\%}$ & $\mathbf{0}$ & $\mathbf{1 0}$ & $\mathbf{2 0}$ & $\mathbf{3 0}$ & $\mathbf{4 0}$ & $\mathbf{5 0}$ & $\mathbf{6 0}$ & $\mathbf{7 0}$ & $\mathbf{7 5}$ & $\mathbf{8 0}$ & $\mathbf{9 0}$ & $\mathbf{1 0 0}$ \\
\hline \hline$K_{r o}$ & 1 & 1 & 1 & 0.94 & 0.80 & 0.44 & 0.16 & 0.045 & 0 & 0 & 0 & 0 \\
\hline$K_{r w}$ & 0 & 0 & 0 & 0 & 0.04 & 0.11 & 0.20 & 0.30 & 0.36 & 0.44 & 0.68 & 1 \\
\hline
\end{tabular}


Table 2. Practical Development Data of a Sandstone Oil Reservoir

\begin{tabular}{|l|l|l|l|l|l|}
\hline $\begin{array}{l}\text { Velocity ratio of } \\
\text { oil and water }\end{array}$ & porosity & $\begin{array}{l}\text { Reservoir } \\
\text { width, } \mathbf{m}\end{array}$ & $\begin{array}{l}\text { Formation } \\
\text { thickness, } \mathbf{m}\end{array}$ & Single well production, $\mathrm{m}^{3} / d$ & residual oil saturation \\
\hline \hline 5 & 0.25 & 140 & $6 \mathrm{~m}$ & 30 & 0.32 \\
\hline
\end{tabular}

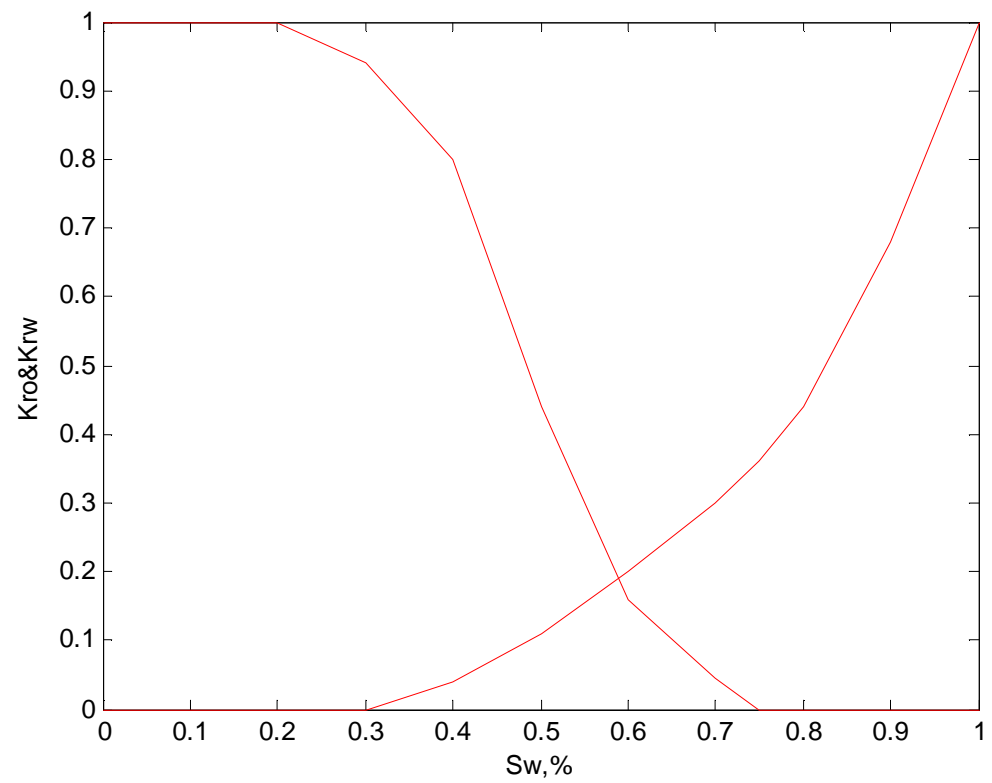

Fig. (1). Broken line graph between effective permeability and saturation

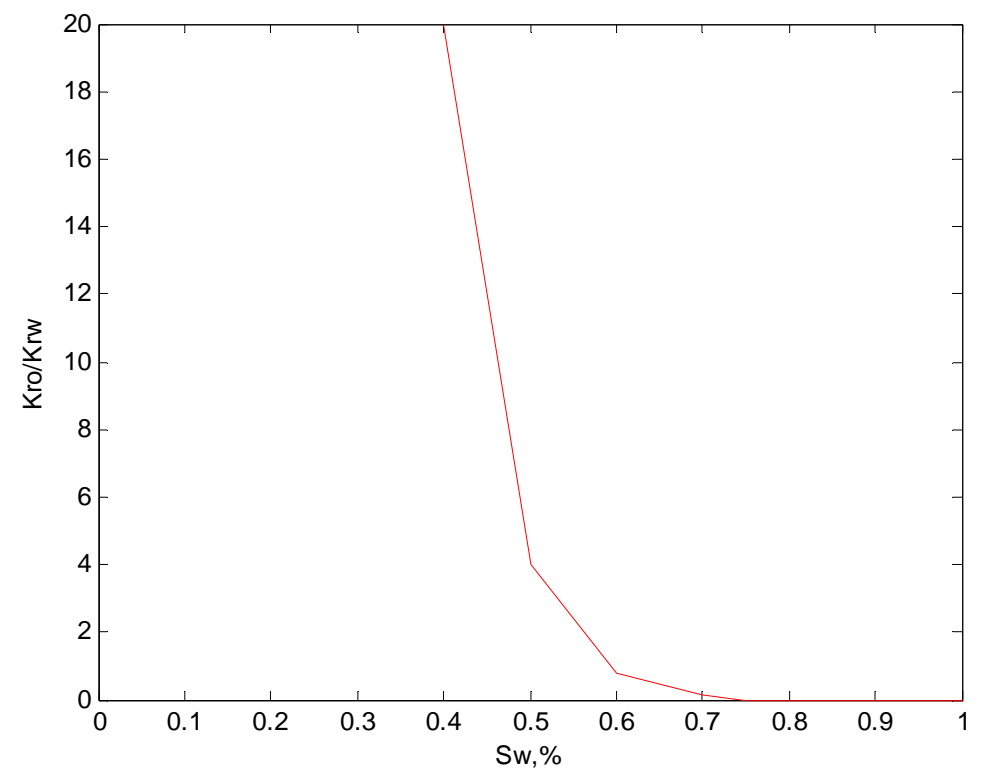

Fig. (2). Broken line graph between effective permeability ratio and water saturation.

From Table 1, we get the broken line graph between effective permeability and saturation, see Fig. (1).

Fig. (1). shows that the oleic permeability decreases by the water saturation; the water phase permeability $k_{w}$ increases by water saturation. From the relation between effective permeability ratio and the given discrete water saturation value, we get the broken line graph between effective permeability ratio and water saturation, see Fig. (2).

Fig. (2) shows that the effective permeability ratio decreases by water saturation.

By using graphical method gives $a=22.39, b=1.52$ and the theoretical expressions: 


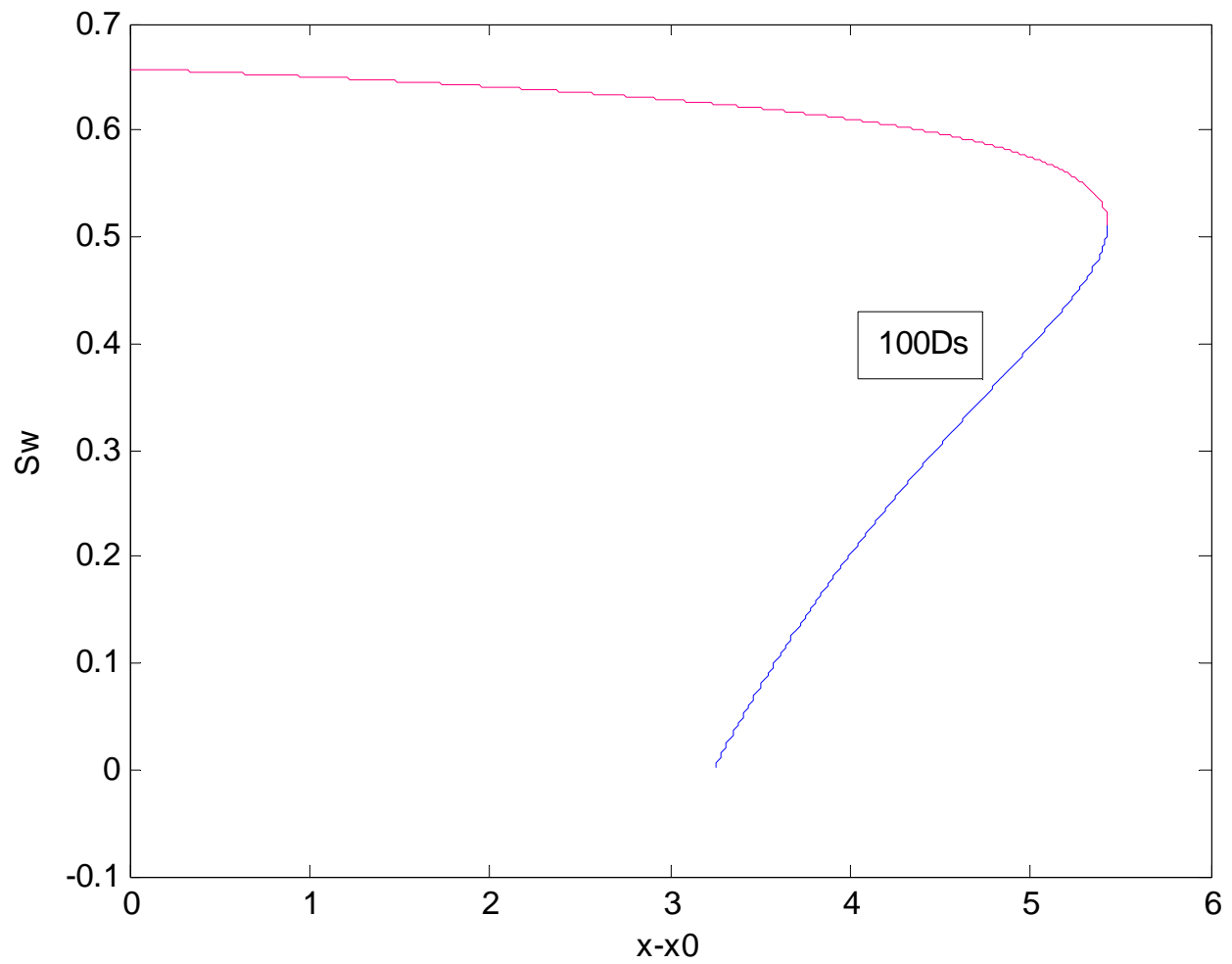

Fig. (3). distribution of water saturation in 100Ds

$S_{w}=\frac{1}{1.52} \ln \frac{1880.8\left(x-x_{0}\right)}{45.6 t-420\left(x-x_{0}\right)+30 t \sqrt{\left.2.3104-\frac{42.56\left(x-x_{0}\right)}{t}\right]}}, 0.01982 t \leq x-x_{0} \leq 0.0543 t$

$S_{w}=\frac{1}{1.52} \ln \frac{1880.8\left(x-x_{0}\right)}{45.6 t-420\left(x-x_{0}\right)-30 t \sqrt{\left.2.3104-\frac{42.56\left(x-x_{0}\right)}{t}\right]}}, 0.0531 t \leq x-x_{0} \leq 0.0543 t$

After fixing the producing time to 100days (Ds) gives Fig. (3).

Fig. (3). shows that, in oil and water seepage area, the water saturation value is positive and multiple in interval [5.31, 5.43] and the value of water saturation is single in interval $[1.982,5.31]$ and decreased by time. Here, the oil recovery $E_{R}$ changes over the water saturation. This new water saturation equation lays a base for the study of residual oil mobility and enhanced oil recovery.

\section{CONCLUSIONS}

1. Theoretical expressions of water saturation in oil-water fluid flow area are established;

2. In oil-water seepage process, $S_{w}$ is continuous in one interval and divergent in another interval;

3. The oil recovery can be re-calculated and improved with this new water saturation function.

\section{NOMENCLATURE}

$$
\begin{array}{ll}
k_{o} & =\text { Oleic permeability } \\
k_{w} & =\text { Water phase permeability } \\
a & =\text { Linear intercept } \\
b & =\text { Linear slope }
\end{array}
$$

$$
\begin{aligned}
& f_{w} \quad=\text { Water cut or fractional flow rate } \\
& M \quad \text { = Viscosity ratio of water and oil } \\
& \phi \quad=\text { Porosity } \\
& A \quad=\text { Seepage flow area } \\
& S_{o r} \quad=\text { Residual oil saturation } \\
& S_{w r} \quad=\quad \text { Irreducible water saturation } \\
& x_{f} \quad=\text { Location of frontal zone in time } t \text {. } \\
& \partial f_{w} / \partial S_{w} \quad=\text { Ratio of change in water cut to change in }
\end{aligned}
$$

\section{CONFLICT OF INTEREST}

None declared.

\section{ACKNOWLEDGMENT}

We would like to acknowledge reviewers and the editor for their many helpful comments and suggestions that improved the manuscript significantly. Thanks are also given to the Natural Science Foundation of China (Grant NO: 50874094) for their support during the completion of this paper. 


\section{REFERENCES}

[1] S.E. Buckley, and M.C. Leverett, "Mechanism of fluid displacements in sands", Trans. AIME, vol. 146, pp. 107-116, 1942.

[2] G.E. Archie, "The electrical resistivity log as an aid in determining some reservoir characteristics", Pet. Trans. AIME, vol. 146, pp. 5462, 1942.

[3] A. Poupon, M.E. Loy, M.P. Tixier, and Schlumberger Well Surveying Corp., "A contribution to electric log interpretation in shaly sands", AIME, vol. 201, pp. 138-145, 1954.

[4] P. Simandoux, "Dielectric measurements of porous media:Application to measurement of water saturations-study of the behavior of argillaceous formations", Revue de L'Institut Franais du Petrole, vol. 18, no. SI, pp. 193-215, 1963.

[5] W. H. Fertl, and G .W. Hammack, "A comparative look at water saturation computation in shaly pay sands" Log Anal., vol. 23, no. 2, pp. 12-20, 1982.
[6] J. Dewan, Essential of Modern Open-Hole Log Interpretation, Penn Well Publishing Company: Oklahoma, 1998.

[7] H. S. Yao, and K.L. Xiang, "Analytical forecasting for water saturation of reservoirs", Syst. Eng. Theory Pract., vol. 3, pp. 137$142,1993$.

[8] C. M. Zhang, and Z.S. Zhang, "Study on theoretical deduction between water flooding resistance and water saturation and on numerical simulation", Sci China Press, vol. 22, no. 2, pp. 151-156, 2008.

[9] P.C. Wang, Z.H. Lv, "A research on the method to calculate water saturation for low resistivity oil pays: a case from Neogene pay of Bohai A oil field", China Offshore Oil Gas, vol. 22, no. 2, pp. 104$107,2010$.

[10] X.L. Li, and L.Q. Ma, "Study on calculation method of reservation water saturation by PND seizing pattern", PI, vol. 24, no. 3, pp. 4648, 2010.

[11] G.S. He, Petroleum physics(in Chinese). Petroleum Industry Press: Beijing, pp. 247-248, 1994.

Received: December 13, 2011

Revised: April 10, 2012

Accepted: April 10, 2012

(C) Liu et al.; Licensee Bentham Open.

This is an open access article licensed under the terms of the Creative Commons Attribution Non-Commercial License (http://creativecommons.org/licenses/by-nc/3.0/) which permits unrestricted, non-commercial use, distribution and reproduction in any medium, provided the work is properly cited. 